\title{
AMBULATORY LAPAROSCOPIC CHOLECYSTECTOMY IS SAFE AND COST-EFFECTIVE: a Brazilian single center experience
}

\author{
Uirá Fernandes TEIXEIRA, Marcos Bertozzi GOLDONI, Mayara Christ MACHRY, \\ Pedro Ney CECCON, Paulo Roberto Ott FONTES and Fábio Luiz WAECHTER
}

Received 22/11/2015

\begin{abstract}
Background - Laparoscopic cholecystectomy is the treatment of choice for gallstone disease, and has been perfomed as an outpatient surgery in many Institutions over the last few years. Objective - This is a retrospective study of a single center in Brazil, that aims to analyze the outcomes of 200 cases of ambulatory laparoscopic cholecystectomy performed by the same Hepato-Pancreato-Biliary team, evaluating the safety and cost-effectiveness of the method. Methods - Two hundred consecutive patients who underwent elective laparoscopic cholecystectomy were retrospectively analyzed; some of them underwent additional procedures, as liver biopsies and abdominal hernias repair. Results - From a total of 200 cases, the outpatient surgery protocol could not be carried out in $22(11 \%)$. Twenty one (95.5\%) patients remained hospitalized for 1 day and $1(4.5 \%)$ patient remained hospitalized for 2 days. From the 178 patients who underwent ambulatory laparoscopic cholecystectomy, $3(1.7 \%)$ patients returned to the emergency room before the review appointment. Hospital cost was on average $35 \%$ lower for the ambulatory group. Conclusion - With appropriate selection criteria, ambulatory laparoscopic cholecystectomy is feasible, safe and effective; readmission rate is low, as well as complications related to the method. Cost savings and patient satisfaction support its adoption. Other studies are necessary to recommend this procedure as standard practice in Brazil.
\end{abstract}

HEADINGS - Laparoscopic cholecystectomy. Ambulatory surgical procedures. Cholelithiasis.

\section{INTRODUCTION}

Cholelithiasis is one of the most common medical conditions in western countries, affecting $10 \%$ to $15 \%$ of the adult population ${ }^{(5,21)}$. Between $1 \%$ and $4 \%$ become symptomatic each year ${ }^{(4,21)}$ and will require treatment. Laparoscopic cholecystectomy (LC) is currently accepted as the gold standard for management of symptomatic gallstone disease ${ }^{(37)}$.

LC remains one of the most frequent surgical procedures performed worldwide. Annually, around 1.5 million patients undergo LC in the United States ${ }^{(13)}$; it is estimated that this number reaches 200,000 patients/ year in the Brazilian public healthcare System ${ }^{(11)}$. After Mühe performed the first LC in $1985^{(29)}$, advances in surgical technique, anesthesia and perioperative care have enabled better results and faster recovery, leading to a progressive decrease in the length of hospital stay ${ }^{(9,24)}$.

Reddick and Olsen reported the first outpatient laparoscopic cholecystectomy in $1990^{(35)}$. Twenty-five years later, debates on the feasibility and safety of the procedure still persist. A number of studies have shown that, with proper selection and discharge criteria, ambulatory laparoscopic cholecystectomy (ALC) can be safely and effectively performed ${ }^{(1,19,44)}$.

Benefits of ALC include patients, hospitals and administrators. Patients experience high levels of satisfaction after surgery and an early return to normal activity $^{(14)}$; the cost-effectiveness allows a greater flow of surgeries and availability of hospital beds, what contributes to the sustainability of the healthcare system and a better management of resources ${ }^{(14,15,16)}$.

Declared conflict of interest of all authors: none

Disclosure of funding: no funding received

Divisão de Cirurgia Hepato-Pancreato-Biliar, Universidade Federal de Ciências da Saúde de Porto Alegre, Hospital Santa Casa de Misericórdia de Porto Alegre, RS, Brasil.

Correspondence: Uirá Fernandes Teixeira. Rua Professor Cristiano Fischer, 818, 802. Petrópolis - CEP: 91410-000 - Porto Alegre, RS, Brasil. E-mail: uiraft@yahoo.com.br 
The purpose of this study was to analyze the outcomes of 200 cases of ALC performed by the same HepatoPancreato-Biliary (HPB) team, evaluating the safety and cost-effectiveness of the method.

\section{METHODS}

Two hundred (200) consecutive patients who underwent elective laparoscopic cholecystectomy were retrospectively analyzed. All subjects were operated by the same HPB team from January 1st, 2013 to June 30th, 2015 at Santa Casa Hospital Complex, in the city of Porto Alegre, Brazil. LC is performed as an outpatient procedure by our group since 2010 , thenceforth being the proposed method to all patients elected for this surgery.

Subjects with symptomatic cholelithiasis and gallbladder polyps associated to gallstones were included in this study. Patients undergoing concomitant procedures, such as umbilical or epigastric hernia repair and liver biopsy were analyzed together.

All subjects were evaluated by the HBP surgical team prior to surgery and tested for cholestasis - Gamma-Glutamyl Transpeptidase (GGT), Alkaline Phosphatase (ALP), Bilirubin levels (BILI), Alanine Aminotransferase (AST), Alaine Transaminase (ALT). Diagnosis was made through abdominal ultrasonography. An 8-hour fasting period was required before surgery and patients reported to the hospital 90 minutes before the proceduce.

A $2 \mathrm{~g}$ single dose of intravenous Cefazolin was administrated 1 hour before surgery for antimicrobial surgical prophylaxis $400 \mathrm{mg}$ of Ciprofloxacin was used in patients allergic to the first choice. Surgery was performed by two surgeons and a scrub nurse. Four surgical ports were positioned according to the American technique after anesthetic infiltration with Ropivacaine $7.5 \%$. At the end of the procedure, pneumoperitoneum was reduced and remade after 3 minutes, and abdominal cavity was evaluated again for bleeding of the liver bed and surgical ports. Additional procedures (hernia repair and liver biopsy), when necessary, were performed subsequently to the cholecystectomy. No cholangiogram was performed in these patients. Drains were placed in a case-by-case basis according to the surgeon's judgment, especially when there was significant inflammation of the hepatic pedicle or bleeding risk in anticoagulated patients.

After surgery, patients were referred to the recovery room with intravenous analgesia and antiemetic medications. They remained in observation for at least 5 hours ( 7 hours on average) and were later reassessed by the surgeon to define hospital discharge or admission.

Criteria for hospital discharge included stable vital signs, proper level of consciousness, capability to walk, no to low abdominal pain, no drains, good acceptance of oral diet and spontaneous diuresis. Patients who qualified for discharge received prescriptions for analgesic and anti-inflammatory drugs (dipyrone, acetaminophen and ketoprofen) and instructions to return to the emergency room if necessary. An appointment for review was scheduled after 15 days of surgery.

\section{RESULTS}

Characteristics of the sample are presented in Table 1. Fifty six $(28 \%)$ patients were male and $144(72 \%)$ patients were female. Mean age was 43.8 years (16-88 years). One hundred ninety $(95 \%)$ patients had cholelithiasis and $10(5 \%)$ patients had gallbladder polyps associated to gallstones. Ten $(5 \%)$ patients underwent LC + umbilical hernia repair, $31(15.5 \%)$ patients underwent LC + liver biopsy; $4(2 \%)$ patients underwent LC + liver biopsy + umbilical hernia repair, $1(0.5 \%)$ patient underwent $\mathrm{LC}+$ umbilical hernia reapir + epigastric hernia repair. There was no conversion to open surgery.

From a total of 200 cases, the outpatient surgery protocol could not be carried out in $22(11 \%)$. Twenty one $(95.5 \%)$ patients remained hospitalized for 1 day and $1(4.5 \%)$ patient remained hospitalized for 2 days. Characteristics of these patients and reasons for hospitalization are displayed in Table 2.

\begin{tabular}{lc} 
TABLE 1 . Characteristics of the sample \\
\hline Age (average / in years) & $43.8(16-88)$ \\
Gender & $56(28 \%)$ \\
Male & $144(72 \%)$ \\
Female & \\
Diagnosis & $200(100 \%)$ \\
Cholelithiasis & $10(5 \%)$ \\
Gallstones + Polyps & $35(17.5 \%)$ \\
Liver abnormalities* & $15(7.5 \%)$ \\
Umbilical hernia & $1(0.5 \%)$ \\
Epigastric hernia &
\end{tabular}

TABLE 2. Characteristics of patients who did not complete the outpatient protocol

\begin{tabular}{lc}
\hline Age (average/in years) & $43.6(27-88)$ \\
Gender & \\
Male & $5(22.7 \%)$ \\
Female & $17(77.3 \%)$ \\
Diagnosis & \\
Cholelithiasis & $22(100 \%)$ \\
Gallstones + Polyps & $2(9.1 \%)$ \\
Liver abnormalities* & $3(13.6 \%)$ \\
Umbilical hernia & $2(9.1 \%)$ \\
Lenght of Hospital Stay & \\
1 day & $21(95.5 \%)$ \\
2 days & $1(4.5 \%)$ \\
Period of the day & \\
Until 14 pm & $7(31.8 \%)$ \\
After 14 pm & $15(68.2 \%)$ \\
Subhepatic drain & \\
Yes & $9(40.9 \%)$ \\
No & $13(59.1 \%)$ \\
Postoperative complications & \\
No & $20(91 \%)$ \\
Nausea / Vomit & $1(4.5 \%)$ \\
Need for ventilatory support & $1(4.5 \%)$ \\
\hline
\end{tabular}

* Elevation of hepatic and/or bile duct enzymes, fatty liver disease or hepatitis. 
From the 178 patients who underwent ALC, $3(1.7 \%)$ patients returned to the emergency room before the review appointment. The first one returned after 7 days complaining of abdominal pain and vomiting. Laboratory tests evidenced 18600 leukocytes, total BILI 1.1; direct BILI 0.6; AST 96; ALT 196; ALP 144; amylase 66; 128 lipase; GGT 281. Abdominal CT revealed a fluid collection without contrast enhancement in the gallbladder bed, measuring $5.0 \times 6.3 \mathrm{~cm}$. MRCP was normal. The patient was admitted for symptomatic treatment (analgesia and antiemetics) and discharged in three days, after clinical and laboratory improvement.

The second patient returned after 3 days, referring abdominal pain and fever. Laboratory tests, abdominal ultrasonography and abdominal CT were normal. The patient was medicated and monitored as an outpatient in the emergency room and discharged after recovery.

The third patient returned after 1 day, reporting headache and vomiting. He was evaluated by the emergency room staff, medicated and shortly discharged. He returned again in 3 days, referring epigastric pain after eating. Abdominal CT and laboratory tests were normal. He was revalued by the surgical team after 15 days, with no complaints.

Finally, comparing 10 patients undergoing outpatient laparoscopic cholecystectomy to 10 patients who remained hospitalized for 1 day, considering the same health insurance and surgical supplies, total hospital cost was on average $35 \%$ lower for the ambulatory group.

\section{DISCUSSION}

LC is the treatment of choice for gallstone disease ${ }^{(37)}$. Over the last few years, advancements in surgical technique, anesthesia and perioperative care allowed its execution as an outpatient surgery ${ }^{(9,38)}$. A number of studies indicate that ALC is feasible, safe and effective ${ }^{(1,19,39,44)}$; cost savings ${ }^{(36)}$ and patient satisfaction ${ }^{(14)}$ are factors in support of its adoption. Standard practice in the United States and Canada, this routine has yet to gain acceptance in other countries. Insecurity among surgeons and patients, along with the lack of defined protocols are the main elements responsible for this controversy.

Selection criteria are considered to be crucial factors in outpatient LC protocols; well-defined and strict parameters have been associated to higher success rates ${ }^{(45)}$. LC is routinely performed as an outpatient procedure by our group, being the proposed method to all patients elected for this surgery. In this analysis, $22(11 \%)$ patients did not complete the ambulatory protocol and $3(1.7 \%)$ patients returned to the emergency room before the review appointment in 15 days, results that overlap the admission (1.6\%-31\%) and readmission (12\%-10\%) rates described before ${ }^{(3,7,8,26,27)}$. This outcome is in accordance with recent studies, which did not find an increase in hospitalizations and readmissions following the adoption of broader criteria $^{(7,41)}$.
Operations performed after 2:00 p.m. and the insertion of surgical drains were the most frequent reasons for hospitalization in our study. Scheduling the procedures in the morning or early afternoon would enable an extended recovery time and a lower chance of admission. Akoh. et al. ${ }^{(3)}$ suggested the application of a topical thrombotic agent during surgery in cases of oozing from the hepatic bed and the execution of exhaustive lavage in order to avoid to the maximum the use of drains. The performance of additional procedures was not detrimental, finding consistent with the report of Psaila et al. ${ }^{(32)}$. Nausea and vomiting are frequent obstacles in the outpatient approach to LC, being accounted for up to $20 \%$ of unplanned admissions s $^{(7,15,18,41,44)}$. In the present report, only one $(4,5 \%)$ patient was admitted due to this cause; administration of prophylactic anti-emetic medication justify this finding ${ }^{(42)}$. The use of Propofol for anesthesia induction ${ }^{(17)}$, avoidance of nitrous oxide ${ }^{(33)}$, use of corticosteroids and cautious use of opioids are other parallel measures. The presence of this complaint in two $(66 \%)$ of the three patients who returned to the emergency room suggests the need to include anti-emetic medication in the discharge prescriptions.

Postoperative pain is also a common limiting factor of ALC protocols, motivating up to $8 \%$ of unexpected hospitalizations ${ }^{(7,34,42)}$. Adequate pain control allows early mobilization, as well as contributes to satisfaction with the procedure. Preoperative wound infiltration with local anaesthetics and the administration of prophylactic analgesics in the recovery room are the main responsible factors to archieve this goal ${ }^{(2,30)}$; some authors suggest intraperitoneal local anaesthetic instillation ${ }^{(6,20-25,43)}$. In our series, three patients returned to the hospital before the review appointment for poorly controlled pain, indicating a need for optimization of pain medication prescriptions at discharge.

The morbidity of $\mathrm{LC}$ is $10 \mathrm{w}^{(12,40)}$. Among the main complications, hemorrhage $(0.25 \%)$ is detected during operation or in the immediate postoperative period and bile duct injury $(0.06 \%)$, if not identified during the procedure, becomes symptomatic in 48 hours $^{(12,40)}$. Therefore, a $24-$ hour observation period offers no advantage in recognizing such conditions, being sufficient 4 to 12 hours $^{(10)}$. In this study, no patients presented major complications. Three patients returned to the emergency room before the review appointment; two returned after one day, what would not be prevented by a 24-hour observation period.

The economic advantage of outpatient surgery is evident ${ }^{(16,36)}$. A cost reduction of $35 \%$ in comparison to inpatient LC was found, as consistent with other reports $(11 \%-46 \%)^{(7,23,27,31)}$. Furthermore, outpatient approach allows a greater flow of surgeries and availability of hospital beds, with a reduced need for staff. The social benefit is observed in the high percentages of patient satisfaction previously described $(85 \%-95 \%)^{(7,8,28)}$ in consequence of proper orientation and early return to normal activity, without the need of hospitalization ${ }^{(16)}$. 


\section{CONCLUSION}

Ambulatory laparoscopic cholecystectomy is safe and cost-effective. As ALC can be reproduced even in primary hospitals in almost all cases, maybe the outpatient procedure will become the standard practice after laparoscopic cholecystectomy.

\section{Authors' contributions}

Data collection: Teixeira UF, Machry MC, Goldoni MB. Execution: Teixeira UF, Goldoni MB, Machry MC. Data analysis: Fontes PRO, Ceccon PN, Waechter FL. Writing and review of the manuscript: Teixeira UF, Fontes PRO, Ceccon PN, Waechter FL, Machry MC.

Teixeira UF, Goldoni MB, Machry MC, Ceccon PN, Fontes PRO, Waechter FL. Colecistectomia laparoscópica ambulatorial é segura e custo-efetiva: a experiência de um centro Brasileiro. Arq Gastroenterol. 2016,53(2): 103-7.

RESUMO - Contexto - A colecistectomia laparoscópica é o tratamento de escolha da colelitíase, e tem sido realizada de maneira ambulatorial em diversas instituições nos últimos anos. Objetivo - Esse é um estudo retrospectivo de um grande centro no Brasil, que tem por objetivo analisar os resultados de 200 casos de colecistectomia laparoscópica ambulatorial realizadas pela mesma equipe de cirurgia Hepato-Pancreato-Biliar, avaliando a segurança e custo-efetividade do método. Métodos - Duzentos pacientes consecutivos submetidos à colecistectomia laparoscópica eletiva foram analisados retrospectivamente; alguns realizaram em conjunto outros procedimentos adicionais, como biópsias hepáticas e reparo de hérnias de parede abdominal. Resultados - De um total de 200 casos, o protocolo de cirurgia ambulatorial não pôde ser concluído em 22 (11\%). Vinte e um $(95.5 \%)$ pacientes permaneceram hospitalizados por 1 dia e um $(4,5 \%)$ paciente por 2 dias apenas. Dos 178 pacientes que foram submetidos à colecistectomia laparoscópica ambulatorial, $3(1,7 \%)$ retornaram à emergência antes da data prevista. O custo hospitalar foi em média 35\% menor no grupo ambulatorial. Conclusão - Com critérios de seleção apropriados, a colecistectomia laparoscópica ambulatorial é factível, segura e custo-efetiva; a taxa de readmissão é baixa, assim como as complicações relacionadas ao método. A redução de custos e a satisfação dos pacientes respaldam sua realização. Outros estudos são necessários para recomendar esse procedimento como padrão no Brasil.

DESCRITORES - Colecistectomia laparoscópica. Procedimentos cirúrgicos ambulatórios. Colelitíase. 


\section{REFERENCES}

1. Ahmad NZ, Byrnes G, Naqvi SA. A meta-analysis of ambulatory versus inpatient laparoscopic cholecystectomy. Surg Endosc. 2008;22:1928-34.

2. Ahn Y, Woods J, Connor S. A systematic review of interventions to facilitate ambulatory laparoscopic cholecystectomy. HPB (Oxford). 2011;13:677-86.

3. Akoh JA, Watson WA, Bourne TP. Day case laparoscopic cholecystectomy: reducing the admission rate. Int J Surg. 2011;9:63-7.

4. Attili AF, De Santis A, Capri R, Repice AM, Maselli S. The natural history of gallstones: the GREPCO experience. The GREPCO Group. Hepatology. 1995;21:655-60.

5. Bates T, Harrison M, Lowe D, Lawson C, Padley N. Longitudinal study of gall stone prevalence at necropsy. Gut. 1992;33:103-7.

6. Boddy AP, Mehta S, Rhodes M. The effect of intraperitoneal local anesthesia in laparoscopic cholecystectomy: a systematic review and meta-analysis. Anesth Analg. 2006;103:682-8.

7. Bona S, Monzani R, Fumagalli Romario U, Zago M, Mariani D, Rosati R. Outpatient laparoscopic cholecystectomy: a prospective study of 250 patients. Gastroenterol Clin Biol. 2007;31:1010-5.

8. Brescia A, Gasparrini M, Nigri G, Cosenza UM, Dall'Oglio A, Pancaldi A, et al. Laparoscopic cholecystectomy in day surgery: feasibility and outcomes of the first 400 patients. Surgeon. 2013;11:S14-8.

9. Bueno Lledo J, Planells Roig M, Arnau Bertomeu C, Sanahuja Santafe A, Oviedo Bravo M, Garcia Espinosa R, et al. Outpatient laparoscopic cholecystectomy: a new gold standard for cholecystectomy. Rev Esp Enferm Dig. 2006;98:14-24.

10. Critchlow JT, Paugh LM. Is 24-hour observation necessary after elective laparoscopic cholecystectomy? South Med J. 1999;92:1089-92.

11. DATASUS [Internet]. Brasília (DF): Ministério da Saúde; 2015 [cited 2015]. Available from: http://datasus.gov.br

12. Deziel DJ, Millikan KW, Economou SG, Doolas A, Ko ST, Airan MC. Complications of laparoscopic cholecystectomy: a national survey of 4,292 hospitals and an analysis of 77,604 cases. Am J Surg. 1993;165:9-14.

13. Dolan JP, Diggs BS, Sheppard BC, Hunter JG. The national mortality burden and significant factors associated with open and laparoscopic cholecystectomy: 1997-2006. J Gastrointest Surg. 2009;13:2292-301.

14. Fassiadis N, Pepas L, Grandy-Smith S, Paix A, El-Hasani S. Outcome and patient acceptance of outpatient laparoscopic cholecystectomy. JSLS. 2004;8:251-3.

15. Fiorillo MA, Davidson PG, Fiorillo M, D’Anna JA, Sithian N, Silich RJ. 149 ambulatory laparoscopic cholecystectomies. Surg Endosc. 1996;10:52-6.

16. Fleming WR, Michell I, Douglas M. Audit of outpatient laparoscopic cholecystectomy. Universities of Melbourne HPB Group. Aust N Z J Surg. 2000;70:423-7.

17. Grundmann U, Silomon M, Bach F, Becker S, Bauer M, Larsen B, et al. Recovery profile and side effects of remifentanil-based anaesthesia with desflurane or propofol for laparoscopic cholecystectomy. Acta Anaesthesiol Scand. 2001;45:320-6.

18. Gurusamy KS, Junnarkar S, Farouk M, Davidson BR. Day-case versus overnight stay for laparoscopic cholecystectomy. Cochrane Database Syst Rev. 2008:CD006798.

19. Gurusamy K, Junnarkar S, Farouk M, Davidson BR. Meta-analysis of randomized controlled trials on the safety and effectiveness of day-case laparoscopic cholecystectomy. Br J Surg. 2008;95:161-8.

20. Gurusamy KS, Nagendran M, Guerrini GP, Toon CD, Zinnuroglu M, Davidson BR. Intraperitoneal local anaesthetic instillation versus no intraperitoneal local anaesthetic instillation for laparoscopic cholecystectomy. Cochrane Database Syst Ver. 2014;3:CD007337.

21. Halldestam I, Enell EL, Kullman E, Borch K. Development of symptoms and complications in individuals with asymptomatic gallstones. Br J Surg. 2004;91:734-8.

22. Henriques AC, Pezzolo S, Gomes M, Godinho CA, Bagarollo CA. Colecistectomia videolaparoscópica ambulatorial. Rev Col Bras Cir. 2001;28:27-29.

23. Jain PK, Hayden JD, Sedman PC, Royston CM, O'Boyle CJ. A prospective study of ambulatory laparoscopic cholecystectomy: training economic, and patient benefits. Surg Endosc. 2005;19:1082-5.

24. Jarrett PEM, Staniszewski A. The development of ambulatory surgery and future challenges. Day surgery: Development and Practice. IAAS. 2006;1:21-34.

25. Jimenez Fuertes M, Costa Navarro D. Outpatient laparoscopic cholecystectomy and pain control: a series of 100 cases. Cir Esp. 2014;93:181-6.

26. Lemos ACP. Colecistectomia Laparoscópica em Ambulatório. Rev Port Cir Amb. 2008;9:35-9.

27. Lezana Perez MA, Carreno Villarreal G, Fresnedo Perez R, Lora Cumplido P, Padin Alvarez H, Alvarez Obregon R. [Laparoscopic cholecystectomy performed as ambulatory major surgery in a regional hospital. Initial results of a series of 110 cases]. Cir Esp. 2010;87:288-92

28. Marinis A, Stamatakis E, Tsaroucha A, Dafnios N, Anastasopoulos G, Polymeneas G, et al. Safety and effectiveness of outpatient laparoscopic cholecystectomy in a teaching hospital: a prospective study of 110 consecutive patients. BMC Res Notes. 2010:3:207.

29. Mühe E. Laparoscopic cholecystectomy. Z Gastroenterol Verh. 1991;26:204-6.

30. Pappas-Gogos G, Tsimogiannis KE, Zikos N, Nikas K, Manataki A, Tsimoyiannis EC. Preincisional and intraperitoneal ropivacaine plus normal saline infusion for postoperative pain relief after laparoscopic cholecystectomy: a randomized double-blind controlled trial. Surg Endosc. 2008;22:2036-45.

31. Planells Roig M, Garcia Espinosa R, Cervera Delgado M, Navarro Vicente F, Carrau Giner M, Sanahuja Santafé A, et al. Ambulatory laparoscopic cholecystectomy. A cohort study of 1,600 consecutive cases. Cir Esp. 2013;91:156-62.

32. Psaila J, Agrawal S, Fountain U, Whitfield T, Murgatroyd B, Dunsire MF, et al. Day-surgery laparoscopic cholecystectomy: factors influencing same-day discharge. World J Surg 2008;32:76-81.

33. Purhonen S, Koski EM, Niskanen M, Hynynen M. Efficacy and costs of 3 anesthetic regimens in the prevention of postoperative nausea and vomiting. J Clin Anesth. 2006;18:41-5.

34. Rathore MA, Andrabi SI, Mansha M, Brown MG. Day case laparoscopic cholecystectomy is safe and feasible: a case controlled study. Int J Surg. 2007:5:255-9.

35. Reddick EJ, Olsen DO. Outpatient laparoscopic laser cholecystectomy. Am J Surg. 1990;160:485-7; discussion 8-9.

36. Rosen MJ, Malm JA, Tarnoff M, Zuccala K, Ponsky JL Cost-effectivenes of ambulatory laparoscopic cholecystectomy. Surg Laparosc Endosc Percutan Tech. 2001;11:182-4.

37. Sain AH. Laparoscopic cholecystectomy is the current "gold standard" for the treatment of gallstone disease. Ann Surg. 1996;224:689-90.

38. Sato A, Terashita Y, Mori Y, Okubo T. Ambulatory laparoscopic cholecystectomy: An audit of day case vs overnight surgery at a community hospital in Japan. World J Gastrointest Surg. 2012;4:296-300.

39. Selim Sözen C凶Ö. Day-Case Laparoscopic Cholecystectomy: Is it a Safe and Feasible Procedure? Eur J Gen Med. 2010;7:372-6.

40. Shamiyeh A, Wayand W. Laparoscopic cholecystectomy: early and late complications and their treatment. Langenbecks Arch Surg. 2004;389:164-71.

41. Sherigar JM, Irwin GW, Rathore MA, Khan A, Pillow K, Brown MG. Ambulatory Laparoscopic Cholecystectomy Outcomes. JSLS. 2006;10:473-8.

42. Steinbrook RA, Gosnell JL, Freiberger D. Prophylactic antiemetics for laparoscopic cholecystectomy: a comparison of perphenazine, droperidol plus ondansetron, and droperidol plus metoclopramide. J Clin Anesth. 1998;10:494-8.

43. Tsimoyiannis EC, Glantzounis G, Lekkas ET, Siakas P, Jabarin M, Tzourou H. Intraperitoneal normal saline and bupivacaine infusion for reduction of postoperative pain after laparoscopic cholecystectomy. Surg Laparosc Endosc. 1998:8:416-20.

44. Vaughan J, Gurusamy KS, Davidson BR. Day-surgery versus overnight stay surgery for laparoscopic cholecystectomy. Cochrane Database Syst Ver. 2013; 7:CD006798.

45. Voyles CR, Berch BR. Selection criteria for laparoscopic cholecystectomy in an ambulatory care setting. Surg Endosc 1997;11:1145-6. 